\title{
Editorial
}

Pediatric

Neurosurgery

Pediatr Neurosurg 2001;35:283

\section{Why Is There CSF?}

\author{
Joseph H. Piatt, Jr.
}

A good mathematical model of a physiological process does not need to explain everything. It is a big success if (1) it is physically intuitive; (2) it reveals deep connections between phenomena not previously known to be related, and (3) it makes predictions that can be tested by experiment. The model of intracranial pulsations presented in this issue by Egnor, Rosiello and Zheng (pages 284-298) is a big success.

Using mathematics familiar to any undergraduate engineering student, the authors have modeled cerebrospinal fluid (CSF) pulsations on a simple electrical circuit with resistance, inductance and capacitance elements. The differential equations arising from such a circuit have been used in the past to describe the behavior of a wide variety of other physical and physiological systems. That no one has ever before thought to apply this model to the cranial cavity is only the first 'Ah ha!' that this paper offers.

The authors proceed to test their model against observations on CSF hydrodynamics yielded by recent advances in magnetic resonance imaging technology. Specifically, they demonstrate that a simple extension of their model predicts the phase shifts in CSF pulsations that have been observed in intracranial cysts and syrinx cavities.

That arterial pulsations and CSF pulsations are nearly synchronous is familiar to anyone who has ever stood at the bedside of a sick patient in a neurosurgical ICU. This synchrony corresponds to resonance in the authors' electrical circuit model, but a state of resonance places a unique constraint on model parameters. Why in human physiology do these parameters take the values that they do and not others? With another extension of their model, the authors demonstrate that resonance is a necessary and sufficient condition for nonpulsatile capillary blood flow, a phenomenon by implication critical for efficient tissue exchanges of metabolic substrates and wastes. Conversely, this extension predicts that critical alterations of heart rate, CSF volume and CSF capacitance will cause the appearance of pulsatile capillary flow - a prediction that begs for experimental verification.

Accepting that nonpulsatile capillary blood flow is a physiological desideratum, the authors' work sheds light on a question that has caused generations of neurosurgeons to shrug their shoulders: 'Why is there CSF?'. The survival advantage of encasing the central nervous system in a rigid, osseous box seems incontrovertible. Within this design specification, however, nonpulsatile capillary flow can only be achieved by provision of a buffer system to protect capillary beds from arterial pulsations. As the authors' model elegantly demonstrates, CSF is that buffer system.

Egnor, Rosiello and Zheng deserve congratulations for a contribution that will likely be cited by all future students of the mechanics of the cranial cavity.

\begin{tabular}{ll}
\hline KARGER & ( ) 2001 S. Karger AG, Basel \\
Fax +4161306 1234 & 1016-2291/01/0356-0283\$17.50/0 \\
$\begin{array}{l}\text { E-Mail karger@karger.ch } \\
\text { www.karger.com }\end{array}$ & $\begin{array}{l}\text { Accessible online at: } \\
\text { www.karger.com/journals/pne }\end{array}$
\end{tabular}

Dr. Joseph H. Piatt, Jr.

Section of Neurosurgery, St. Christopher's Hospital for Children

Erie Avenue at Front Street

Philadelphia, PA 19134-1095 (USA)

Tel. +1 215427 4340, Fax +1 215427 4638, E-Mail joseph.piatt@tenethealth.com 